ORIGINAL ARTICLE

\title{
Integrin $\alpha 11 \beta 1$ regulates cancer stromal stiffness and promotes tumorigenicity and metastasis in non-small cell lung cancer
}

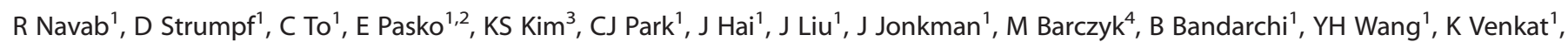

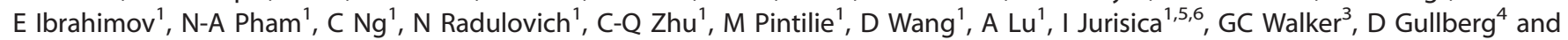
M-S Tsao ${ }^{1,2,6}$

Integrin $a 11 \beta 1$ is a stromal cell-specific receptor for fibrillar collagens and is overexpressed in carcinoma-associated fibroblasts (CAFs). We have investigated its direct role in cancer progression by generating severe combined immune deficient (SCID) mice deficient in integrin a11 (a11) expression. The growth of A549 lung adenocarcinoma cells and two patient-derived non-small cell lung carcinoma (NSCLC) xenografts in these a11 knockout $\left(\mathrm{a}_{11^{-/}}\right)$mice was significantly impeded, as compared with wild-type $\left(\mathrm{a} 11^{+/+}\right)$SCID mice. Orthotopic implantation of a spontaneously metastatic $\mathrm{NCl}-\mathrm{H} 460 \mathrm{SM}$ cell line into the lungs of a $11^{-/-}$and $\mathrm{a}_{11} 1^{+/+}$mice showed significant reduction in the metastatic potential of these cells in the $a 11^{-/-}$mice. We identified that collagen cross-linking is associated with stromal a11 expression, and the loss of tumor stromal a11 expression was correlated with decreased collagen reorganization and stiffness. This study shows the role of integrin a11 $\beta 1$, a receptor for fibrillar collagen in differentiation of fibroblasts into CAFs. Furthermore, our data support an important role for a11 signaling pathway in CAFs, promoting tumor growth and metastatic potential of NSCLC cells and being closely associated with collagen cross-linking and the organization and stiffness of fibrillar collagen matrices.

Oncogene (2016) 35, 1899-1908; doi:10.1038/onc.2015.254; published online 6 July 2015

\section{INTRODUCTION}

The biology of carcinomas is significantly influenced by the tumor microenvironment, which includes extracellular matrix, blood vasculature, inflammatory cells and fibroblasts. ${ }^{1-4}$ Recent studies have shown the contribution of stromal fibroblasts to cancer initiation and progression, ${ }^{5-7}$ providing a rationale for development of therapeutics against novel stromal targets. ${ }^{8,9}$

Integrins constitute a family of homologous transmembrane, cell-matrix adhesion receptors expressed on all nucleated cells, including tumor and tumor-associated host cells such as endothelial cells and leukocytes, also present in the tumor microenvironment. ${ }^{10,11}$ Leukocytes and endothelial cells express multiple integrins including members of the $\beta 2$ subfamily (leukocytes) and members of the av integrin subfamily (endothelial cells). ${ }^{10,11}$ Integrins have not only been implicated as mediators of tumor cell proliferation, migration and invasion, but also as multifunctional receptors in the tumor stroma. ${ }^{11}$ They are grouped into subfamilies on the basis of $\beta$-subunit associations, characteristics of the a subunit or the identity of partnering ligands. All four collagen-binding integrins (a1, a2, a10 and a11) heterodimerize with $\beta 1$-subunit ${ }^{12,13}$ and bind native collagens via their respective a l-domains, which recognize GFOGER motifs. ${ }^{10,14-17}$ Collagen-binding integrins are involved in cell adhesion, cell migration, remodelling of collagen lattices and regulation of collagen turnover. ${ }^{18,19}$

In our previous study, using the representational difference analysis technique, ITGA11 (integrin a11, a11) was among the top six genes identified as differentially expressed in non-small cell lung carcinoma (NSCLC) tumor stroma compared with the stroma of normal lung. ${ }^{20}$ Furthermore, we confirmed that a11 is overexpressed in NSCLC-associated stromal fibroblasts compared with matched normal fibroblasts. ${ }^{21,22}$ Our co-implantation studies using NSCLC cells and SV40-immortalized mouse embryonic fibroblasts (MEFs) have demonstrated that a11 expression in MEFs significantly promotes tumorigenesis. ${ }^{21}$ These data provided a rationale for exploring the effect of stromal integrin a11 on tumor progression of lung cancer cells.

It is now well recognized that tumor initiation, growth, invasion and metastasis result from a complex interplay between the host microenvironment and the cancer cell. ${ }^{23}$ The biological role of the tumor microenvironment in human lung cancer has not been studied in depth. Here, we have studied the direct role of stromal integrin a11 on the growth and metastasis of non-small cell lung cancer cells using novel immune-compromised a11-deficient mice. Our results suggest that a11 is closely associated with collagen cross-linking and stiffness within cancer stroma, thus providing additional insights on stromal regulation of tumor growth and metastasis in NSCLC.

\section{RESULTS}

Impact of stromal a11 deficiency on the growth of NSCLC cells To generate the a11-deficient mouse strain, a null mutation was introduced into the mouse Itga11 gene by gene targeting. ${ }^{18}$ The

\footnotetext{
${ }^{1}$ Princess Margaret Cancer Center and Campbell Family Institute for Cancer Research, University Health Network, Toronto, Ontario, Canada; ${ }^{2}$ Department of Laboratory Medicine and Pathobiology, University of Toronto, Toronto, Ontario, Canada; ${ }^{3}$ Department of Chemistry, University of Toronto, Toronto, Ontario, Canada; ${ }^{4}$ Department of Biomedicine and Centre of Cancer Biomarkers, University of Bergen, Bergen, Norway; ${ }^{5}$ Department of Computer Science, University of Toronto, Toronto, Ontario, Canada and ${ }^{6}$ Department of Medical Biophysics, University of Toronto, Toronto, Ontario, Canada. Correspondence: Dr M-S Tsao, Department of Medical Biophysics and Laboratory Medicine and Pathobiology, University Health Network, 200 Elizabeth Street, 11th floor, Toronto, ON M5G2C4, Canada.
}

E-mail: ming.tsao@uhn.on.ca

Received 24 November 2014; revised 23 April 2015; accepted 29 May 2015; published online 6 July 2015 
a11-deficient heterozygous $\mathrm{C} 57 \mathrm{BL} / 6 \mathrm{~J}$ mice $(+/-)$ were originally in a mixed C57BL/6 and $129 \mathrm{SvJ}$ background. These mice have been back-crossed at least 10 times to reach a homogenous C57BL/6 background. Subsequently, they were bred with the $\mathrm{BALB} / \mathrm{c}$ severe combined immune deficient (SCID) mice for seven generations producing a11-deficient heterozygous $(+/-)$ in a SCID background (see Supplementary information, Supplementary Figures S1a and d).

To evaluate the effect of stromal a11 on the growth of human NSCLC cells, we implanted A549 lung adenocarcinoma cells into the subcutaneous tissue of a11 wild-type $\left(a 11^{+/+}\right)$, heterozygous $\left(\mathrm{a} 11^{+/-}\right)$and homozygous-deleted $\left(\mathrm{a}_{111^{-/-}}\right)$SCID mice. The growth of the A549 cell line was impeded significantly in a $11^{-1-}$ compared with $a 11^{+/+}$mice $(P<0.00001)$ (Figure 1 a and Supplementary Figure S1e). This effect was also demonstrated using cell lines derived from primary human lung adenocarcinoma xenografts, PHLC $178(P<0.0001$; Figure 1b) and PHLC 655 $(P=0.05$; Figure 1c).

It has been reported that collagen-binding integrin receptors control the growth hormone/IGF-1-dependent biological activities in mice with a combined deficiency of the $\alpha 2 \beta 1$ and $\alpha_{11 \beta 1}$ integrins, thus lacking the major receptors for collagen type I. $^{24}$ To exclude the possibility that the reduced growth rates are due to this secondary pathway, we measured the circulating IGF-1 and
IGFBP-3 levels in the sera of $a 11^{-/-}$and $a 11^{+/+}$mice when the xenograft tumors reached the maximum size of $1.5 \mathrm{~cm}$. The levels of circulating IGF-1 and IGFBP-3 were similar in both groups of mice (Supplementary Figures S1f and g).

To evaluate the lack of a11 in tumor stroma, immunohistochemistry on frozen sections of the tumor xenografts confirmed the presence of mouse $a 11$ in the tumor stroma of $a 11^{+/+}$mice (Supplementary Figures S2a and b) and the lack of mouse a11 in the tumor stroma of ${\mathrm{a} 11^{-/-}}^{-}$mice (Supplementary Figures S2c and d). To characterize the tumor stroma in $a 11^{-/-}$mice, serial sections of formalin-fixed paraffin-embedded xenograft tumors were stained with hematoxylin and eosin and PicroSirius red and immunostained for cytokeratin (Supplementary Figure S3). Using the Picrosirius red staining which stains all types of collagen fibers including fibrillar collagens, we did not observe any difference in collagen fiber staining in tumor stroma of a $11^{-/-}$xenograft tumors versus $\mathrm{a} 11^{+/+}$. We used a-smooth muscle actin (a-SMA) staining (Figure $1 \mathrm{~d}$ ) to quantify the relative abundance (represented by pixels) of activated fibroblasts in the mouse tumor stroma in the three subcutaneous xenograft tumors models using the Aperio ImageScope Version 11.2.0.780. The pixel counts showed a decrease in a-SMA-positive pixels in $a 11^{-/-}$xenograft tumors as compared with $a 11^{+/+}$mice (Supplementary Figure S4a). a

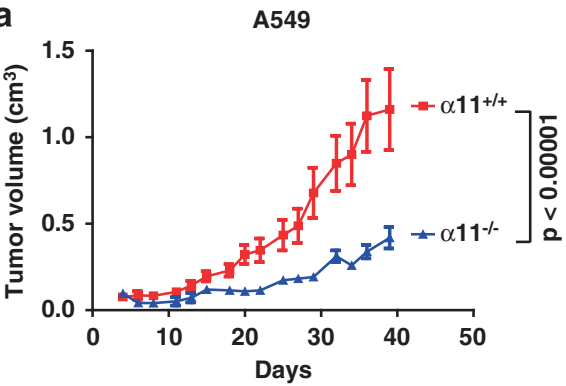

b

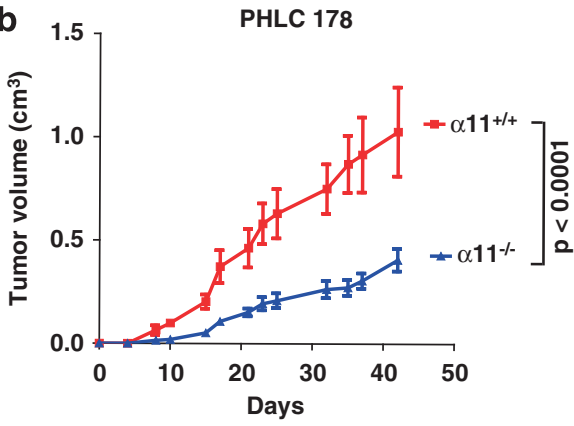

C

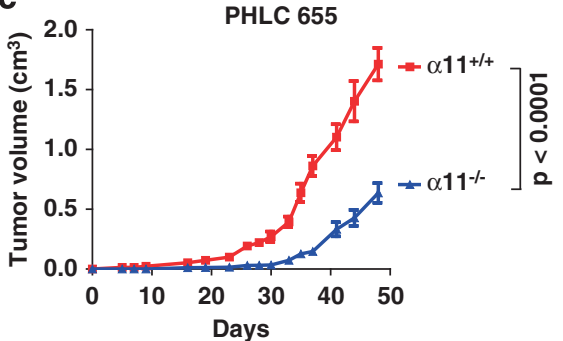

d
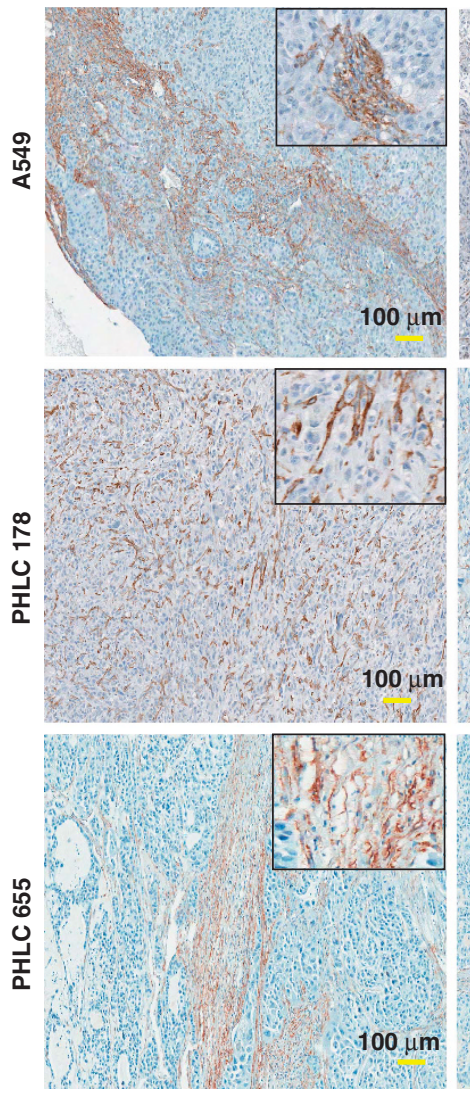

$\alpha 11^{-1 / S C I D}$ mice
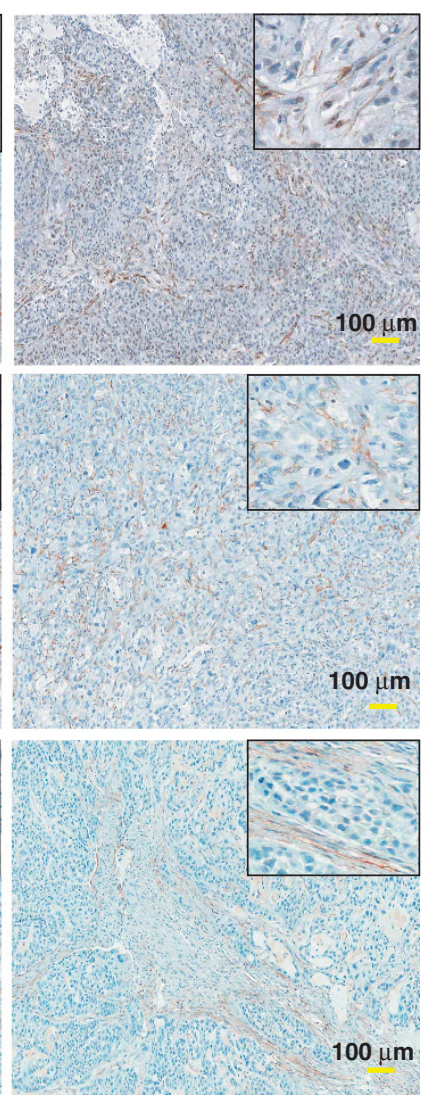

Figure 1. Tumorigenicity of NSCLC cells was impeded in SCID mice with a homozygous deleted $\alpha 11$ genotype and is related to differentiation of fibroblasts to myofibroblasts (CAFs). (a) A total of $2 \times 10^{6}$ of either lung adenocarcinoma (A549) cells or primary adenocarcinoma lung cancer cell lines PHLC 178 (b) and PHLC 655 (c) were implanted subcutaneously into the flank of SCID mice with normal (+/+) and homozygous $(-/-)$ deleted $\alpha 11$. Tumor growth was monitored and recorded every other 2 days. The data are represented as mean \pm s.e.m. $(n=10)$. (d) Representative images of serial sections of formalin-fixed paraffin-embedded xenograft tumors from three subcutaneous xenograft tumors models were immunostained for $\alpha$-SMA; scale bar, $100 \mu \mathrm{m}$. Images were taken at $\times 10$ magnification. The top right corner of each micrograph showing $\times 3$ magnification of each image. 
A549-induced a11-associated tumor stromal gene expression changes

We previously reported a set of differentially expressed genes that were induced $\geqslant$ four fold in tumors formed by co-implantation of A549 cells with the SV40 immortalized $a 11^{+/+}$compared with a $11^{-1-}$ MEFs. ${ }^{21}$ We called this the exogenous stromal model. ${ }^{22}$ To identify potential mediators of tumor growth promotion associated with integrin a11ß1, we compared the global gene expression profiles of A549 tumors formed in $a 11^{-/-}$ versus $\mathrm{a} 11^{+/+}$mice, and named it the endogenous stromal model. In agreement with the immunostaining data, the expression levels of mouse Acta2 (a-SMA) was lower in xenograft tumors formed in $\mathrm{a}_{111^{-/-}}$compared with $\mathrm{a} 11^{+/+}$mice (Supplementary Data Set S1a). In addition to observing this for A549 tumors, reduced Acta2 levels in $a 11^{-/-}$mice was also confirmed in two additional PHLC tumor xenograft models (Figure 1d; Supplementary Figure S4b). Furthermore, higher a-SMA protein levels were observed in primary cancer associated fibroblast (CAF) cell lines compared with their matched normal fibroblast (NF) counterparts (Supplementary Figure S4c). This was further investigated in hTERT (human Telomerase Reverse Transcriptase) immortalized NF cell lines ${ }^{22}$ with different levels of ITGA11gene expression (NF 094 YFPhTERT, low a11 and NF $094^{\text {YFPhTERT, high a11) }}$ (see Supplementary Information; Supplementary Figure S4c), which demonstrated a positive correlation between a11 levels and a-SMA expression (Supplementary Figure S4c).
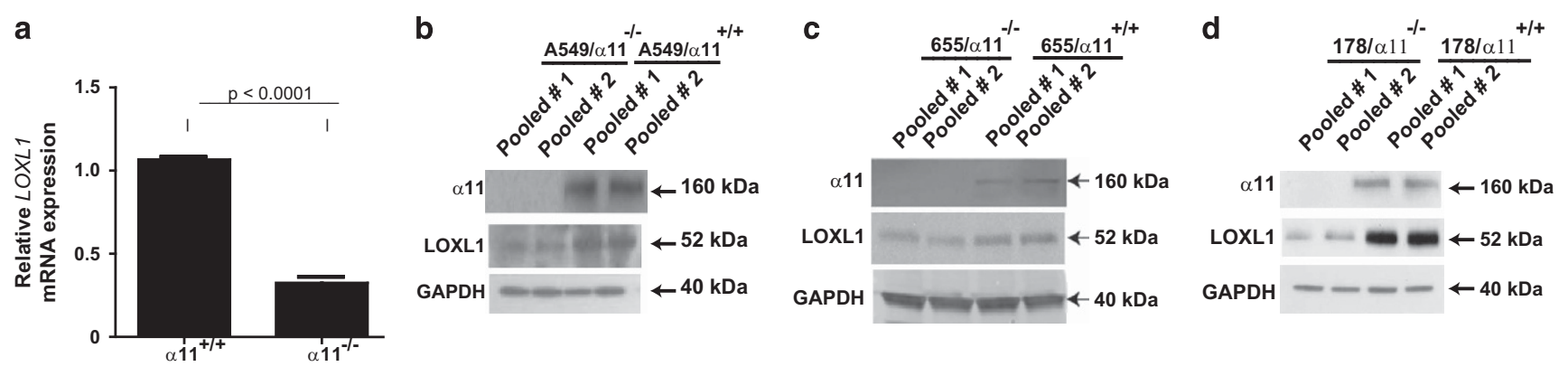

To identify the gene expression changes in A549 tumor cells or in $a 11^{-/-}$and $a 11^{+/+}$mouse tumor stroma, we profiled the tumor-derived RNA using the Mouse WG-6v2 Illumina and Human HT-12v4 Bead Chips (see Supplementary Information; Supplementary Data Set S1a-d). We identified 342 (124 downregulated and 218 upregulated) mouse stromal genes that were differentially expressed by at least 1.5 -fold in the A549 tumor stroma in $\mathrm{a} 11^{-/-}$compared with $\mathrm{a} 11^{+/+}$mice (Supplementary Data Set S1a and b; Supplementary Figure S5a). Using the human chip, we identified 2687 (1271 downregulated and 1416 upregulated) genes whose expression in cancer cells was influenced by a11 expression in the tumor stromal fibroblasts (Supplementary Data Set S1c and d; Supplementary Figure S5b). The expression changes of 8 mouse and 11 human genes were validated using reverse-transcription qPCR (RT-qPCR) (Supplementary Figures $\mathrm{S} 5 \mathrm{C}$ and $\mathrm{d}$ ).

Among the $\mathrm{a} 11^{-/-}$-associated downregulated genes in stroma of the A549 xenograft tumors was the collagen cross-linking gene, lysyl oxidase-like 1 (Loxl1) (Supplementary Data Set S1a, Figures $2 \mathrm{a}$ and b). Downregulation of LOXL1 expression was further confirmed in PHLC 655 and PHLC 178 tumor xenografts in $\mathrm{a}_{1} 1^{-/-}$versus $\mathrm{a} 11^{+/+}$mice (Figures $2 \mathrm{c}$ and $\mathrm{d}$ ). To explore the relevance of $a 11$ and LOXL1 gene expression in the context of NSCLC stroma versus normal lung, we used our published microarray data using Affymetrix Exon 1.0 ST oligonucleotide array on 15 laser-capture microscope tumor stroma and

f

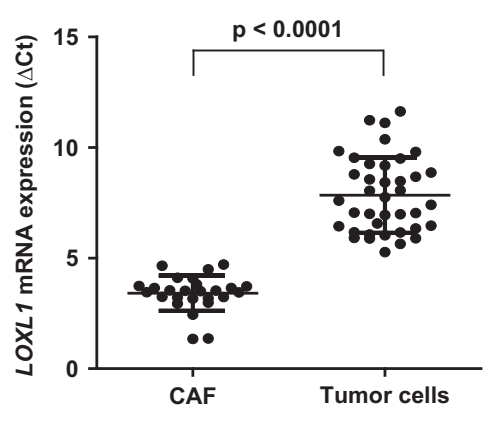

g

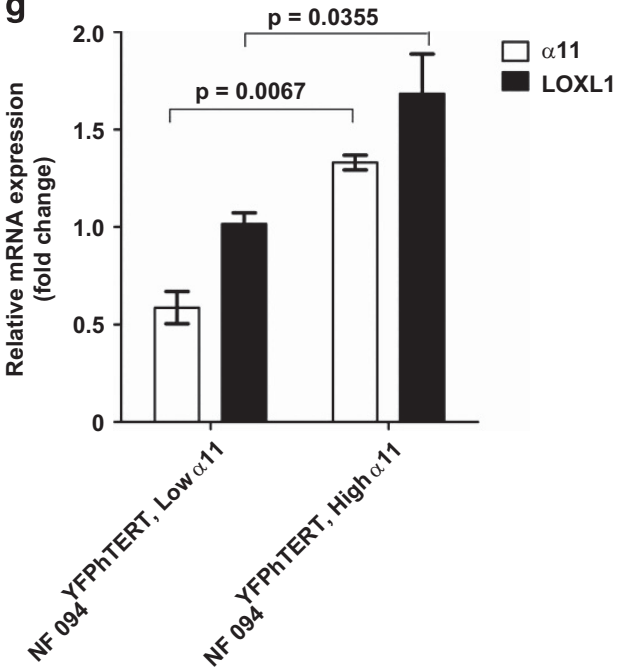

Figure 2. Correlation between ITGA11 and LOXL1 gene expression. (a) RT-qPCR for LOXL1 gene expression in A549 xenograft tumors in $\alpha 11^{-1-}$ compared with $\alpha 11^{+/+}$mice. (b and c) Western blot analysis showing absence of mouse $\alpha 11$ and decrease of LOXL1 proteins in A549 (b), PHLC 655 (c) and PHLC 178 (d) tumor xenografts from $\alpha 11^{-1-}$ compared with $\alpha 11^{+/+}$mice (eight tumor xenografts were pooled into two groups). (e) Correlation between LOXL1 and a11 gene expression from microarray data using Affymetrix Exon 1.0 ST oligonucleotide array on 15 lasercapture microscope (LCM) tumor stroma and corresponding normal lung tissue from 15 NSCLC primary tumors (Spearman $r=0.7925$; $P$ value $<0.0001$ ). (f) RT-qPCR representing a comparison of LOXL1 gene expression in 20 CAFs and 41 lung cancer tumor cell lines. $\Delta C t$ indicates higher values correspond to lower gene expression levels. (g) RT-qPCR results show a significant correlation between LOXL1 and a11 gene expression in NF 094 YFPhTERT, low $\alpha 11$ and NF 094 ${ }^{\text {YFPhTERT, high } \alpha 11}$ cell lines. 
corresponding normal lung tissue from the same 15 NSCLCs that were used to establish CAFs and NFs. ${ }^{22}$ There was a significant correlation between the LOXL1 and a 11 gene expression in NSCLC stroma versus normal lung (Spearman $r=0.7925 ; P$ value $<0.0001$ ) (Figure 2e). Using RT-qPCR, we surveyed the expression of LOXL1 in a panel of 20 human lung cancer-derived CAF and 41 NSCLC cell lines. We observed relatively low LOXL1 levels across all NSCLC cell lines (Figure 2f). The correlation between LOXL1 and a11 gene expression was also observed in NF 094 YFPhTERT, low a11 and NF $094^{\text {YFPhTERT, high a11 }}$ cell lines $^{22}$ (see Supplementary Information; Figure 2g).

Protein-protein interaction (PPI) network reveals genes/proteins regulated by a11

The Gene Set Enrichment Analysis for the downregulated genes on the mouse-specific microarray for A549 xenografts in a $11^{-1-}$ versus $\mathrm{a} 11^{+/+}$SCID mice indicated a significant enrichment in genes annotated to the Biocarta integrin signaling pathway (see Supplementary Information).

A PPI network of potential direct PPIs between the downregulated genes and integrin-mediated signaling pathway genes revealed a PPI between the focal adhesion kinase/protein tyrosine kinase 2 (FAK/PTK2) and genes/proteins belonging to the integrinmediated pathway (Supplementary Figure S6). ${ }^{25}$ Western blot analysis showed reduced phosphorylation of FAK and the extracellular signal-regulated kinase (Erk) proteins in A549 xenografts from integrin $\mathrm{a}_{11^{-/-}}$versus $\mathrm{a} 11^{+/+}$mice (Figures $3 a$ and c). Additional putative associations of downregulated genes with proteins of the integrin-mediated signaling pathway were observed in the PPI networks, suggesting a broad involvement for genes regulated by integrin a11 (Supplementary Figure S6).

Matrisome components contribute to tumor and stromal cell cross-talk

We hypothesized that the putative functions of the differential downregulated gene expression changes in human epithelial

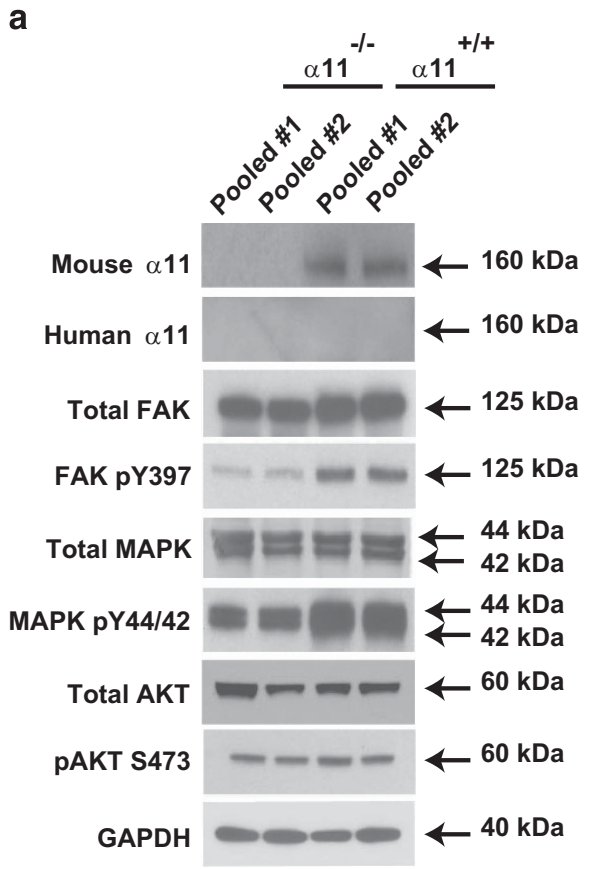

tumor and mouse stroma may reflect on tumor-stroma interactions via extracellular/secreted proteins. We therefore focused on the human and mouse downregulated matrisomal genes (glycoproteins, collagens, proteoglycans, extracellular matrix (ECM) affiliated, ECM regulators and secreted factors; see Supplementary Information; Figure 4). Further PPI analysis revealed networks between several of the downregulated genes and fibrillar collagens (for example, biglycan, bone morphogenetic protein1; Figure 4, light blue shading). Importantly, the analysis points to potential associations of downregulated genes with growth factors in pathways previously implicated in CAF differentiation and tumorigenesis (Figure 4, yellow shading) including latent transforming growth factor beta binding protein 3 (LTBP3) and latent transforming growth factor beta binding protein 4 (LTBP4) association with transforming growth factor beta 1 (TGFB1), transforming growth factor beta 2 (TGFB2) (TGF $\beta$ signaling); WNT1 inducible signaling pathway protein 2 (WISP2), insulin-like growth factor binding protein 2 (IGFBP2), insulin-like growth factor binding protein 4 (IGFBP4) association with insulin-like growth factor 1 (IGF1) and insulin-like growth factor 2 (IGF2) (IGF signaling); syndecan 4 (SDC4) association with fibroblast growth factor 2 (FGF2) (FGF signaling); semaphorin $3 \mathrm{~F}$ (Sema3f) and glypican 1 (Gpc1) with vascular endothelial growth factor A (VEGFA) (VEGF signaling); fibulin 1 (FBLN1) and latent transforming growth factor beta binding protein 3 (Ltbp3) with heparin-binding EGF-like growth factor (HBEGF) (signaling via heparan sulfate proteoglycans and EGFR). Taken together, the potential association of matrisomal deregulated genes in key pathways provides additional insight into how ITGA11 may affect CAF differentiation and tumorigenesis. This is in accordance with the observed phenotypes showing reduced tumor growth and defects in CAF differentiation in A549 xenografts in integrin $a 11^{-/-}$versus integrin $a 11^{+/+}$mice.

a11 promotes fibrillar collagen reorganization and tissue stiffness We next examined whether integrin a11 has a role in collagen stiffness in tumor xenografts. Microscopic analysis of paraffin sections of $\mathrm{a}_{11^{-/-}}$and $\mathrm{a} 11^{+/+}$tumor xenografts revealed the

b
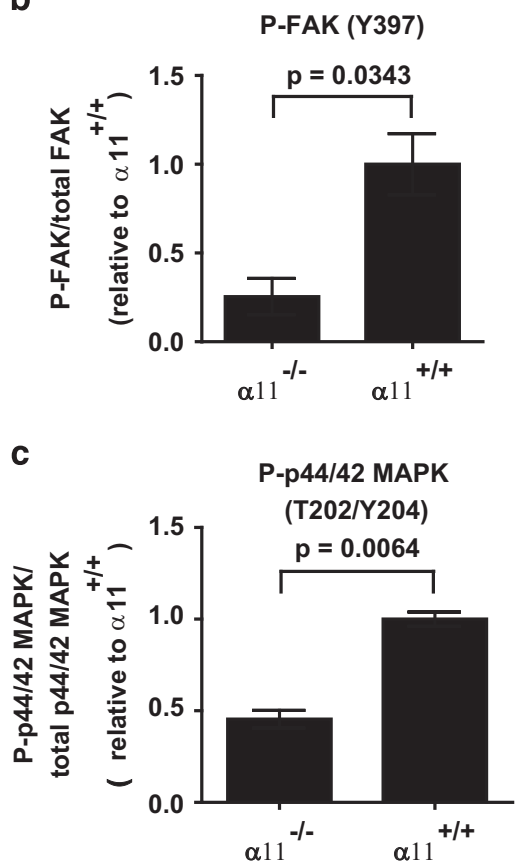

Figure 3. Lack of $\alpha 11$ in NSCLC xenograft tumors showed a decrease in FAK and protein tyrosine kinase 2 (PTK2) activity. (a) Western blot analysis was performed on eight tumor xenografts from $\alpha 11^{-/-}$and $\alpha 11^{+/+}$mice (pooled into two groups) to detect phosphorylation levels of intermediate molecules involved in the integrin signaling pathway such as FAK and PTK2. (b and c) Densitometry was used to quantify the phosphorylation levels using the Image $J$ analysis software (http://imagej.nih.gov/ij/index.html). 


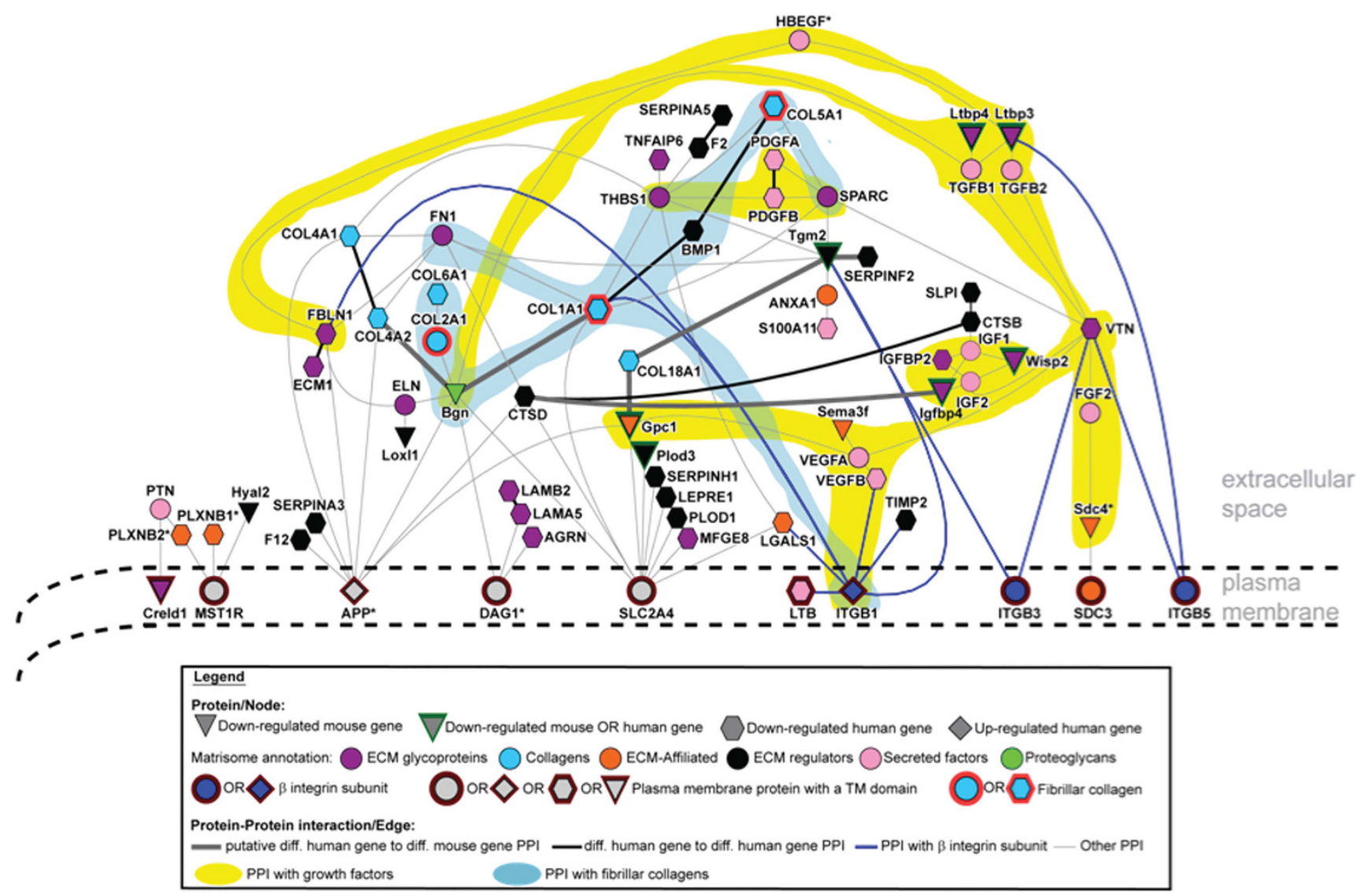

Figure 4. The putative functional effect of transcriptional downregulation of matrisomal genes on the tumor microenvironment. Human and mouse differentially downregulated genes (DDG) annotated as matrisomal proteins were matched to PPI in I2D and the resulting PPI network was visualized in NAViGaTOR (see Supplementary Information). A subset of PPI from this network, shown here, containing 38 human matrisomal DDG and 13 mouse matrisomal DDG, represents potential direct PPI between human matrisomal DDG (black PPI/edges), or with mouse matrisomal DDG (thick grey edges), PPI via other matrisomal proteins or with plasma membrane proteins (thin grey edges), and with $\beta$ integrin proteins (blue edges). PPI of downregulated genes with growth factors or with fibrillar collagens are highlighted by yellow and light blue shading, respectively. Node/protein color indicates matrisome annotation categories or $\beta$ integrin. Additional annotation of proteins is also indicted by a colored rim around each node: Red-Gene Ontology GO:0005583 fibrillar collagen; Brown-Plasma membrane protein (brown); Green-Genes differentially downregulated on both human and mouse microarrays. Node shape indicates deregulation as indicted in the legend. Gene Name is provided with human and mouse naming convention. The cellular context may apply to the tumor cells (human), stroma cells (mouse) or both, and is based on the annotation of individual proteins as matrisomal proteins and/or plasma membrane proteins. Asterisk in the gene name indicates a protein for which secreted and membrane-bound isoforms are described. Some nodes and edges were faded-out from the original PPI network to reduce the complexity of this network/image.

progressive non-linearization of the collagen adjacent to the tumor cells in $\mathrm{a} 11^{-1-}$ as compared with a $11^{+1+}$ mice (Figure $5 \mathrm{a}$, top and middle panels). Furthermore, Second Harmonic Generation (SHG) imaging which illuminates almost exclusively fibrillar collagen ${ }^{2}$ confirmed the lack of collagen organization in tumor xenografts formed in $\mathrm{a}_{1} 1^{-/-}$versus $\mathrm{a} 11^{+/+}$mice (Figure 5a, bottom panels and Supplementary Figure $\mathrm{S7a}$, top and bottom panels). The total amount of fibrillar collagen was significantly reduced in A549, PHLC 178 and PHLC 655 xenografts in $\mathrm{a} 11^{-/-}$versus $\mathrm{a} 11^{+/+}$mice (Supplementary Figure S7b). Quantitative analysis of collagen fiber orientation in tumor xenografts from $\mathrm{a}_{1} 1^{-/-}$versus $\mathrm{a} 11^{+/+}$mice showed a significant correlation between collagen fiber arrangement and a11 expression (Supplementary Figure S7c).

Height images obtained from atomic force microscopy (AFM) (Figure $5 \mathrm{~b}$ ) revealed dispersed holes on the surface of $a 11^{-/-}$ samples, indicative of the lack of collagen organization. Moreover, AFM elasticity measurements (Figures $5 \mathrm{c}$ and d) showed significantly higher modulus values in tumor xenografts formed in $\mathrm{a} 11^{+/+}$versus $\mathrm{a} 11^{-/-}$mice, presumably due to greater reorganization activity of collagen fibrils by integrin $a 11 \beta 1-$ expressing cells. a11 promotes the metastatic potential of $\mathrm{NCl}-\mathrm{H} 460 \mathrm{SM}$ cells

To evaluate whether integrin a11 has a role in promoting the metastatic potential of NSCLC cells, we performed orthotopic implantation of $\mathrm{NCl}-\mathrm{H} 460 \mathrm{SM}$ lung carcinoma cells in integrin $\mathrm{a}_{11^{-/-}}, \mathrm{a}_{11} 1^{+/-}$and $\mathrm{a} 11^{+/+}$mice (see Supplementary Information). The H460SM cell line was previously established for its ability to metastasize spontaneously when implanted into the lungs of nude rats. ${ }^{25}$ H460SM cells formed primary tumor growth equally well in all groups: $a 11^{+/+}(16 / 16), a 11^{+/-}(9 / 9)$ and $a 11^{-/-}(13 / 14)$ mice. While systemic metastasis to bone, kidney and brain were found in all $a 11^{+/+}(16 / 16)$ mice, significant reduction was noted in a $11^{+/-}(1 / 9)$ and $a 11^{-1-}(3 / 14)$ mice, suggesting contribution of stromal a11 expression to lung cancer metastasis (Table 1).

\section{DISCUSSION}

We have demonstrated directly using an in vivo a11 endogenous model in SCID mice that stromal a11 expression affects the tumorigenicity and metastatic potential of NSCLC cells. Furthermore, we showed that the expression of collagen cross-linking gene, LOXL1, is associated with stromal a11 expression, and that 
a
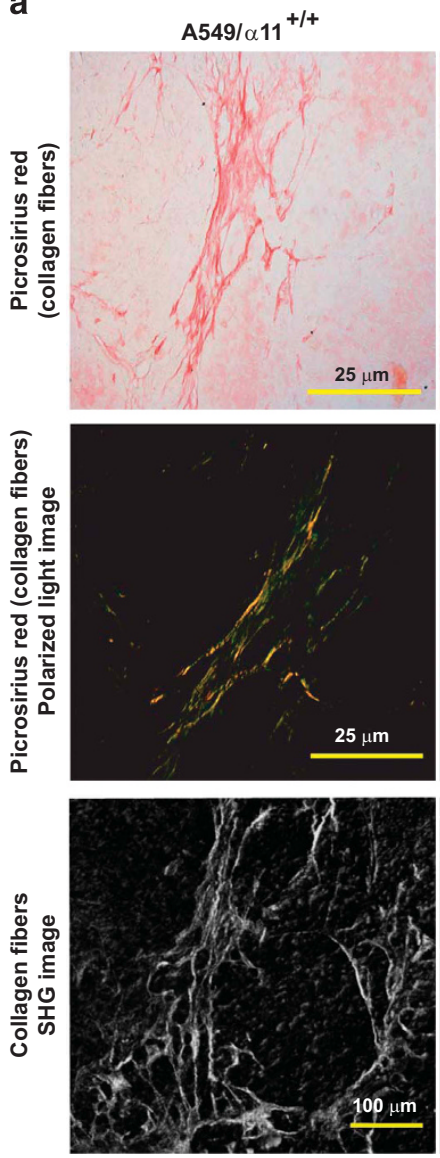

A549/ $\alpha 11^{-/-}$

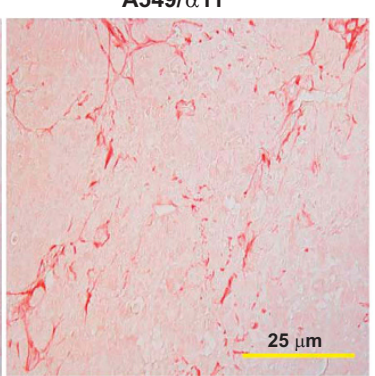

b

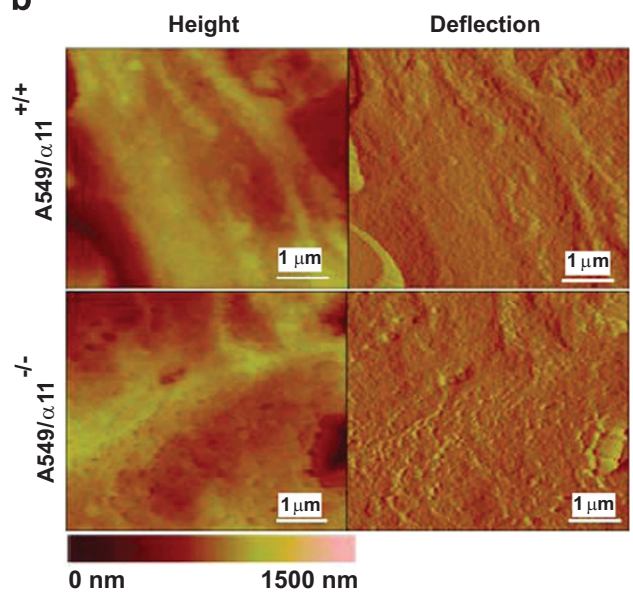

C

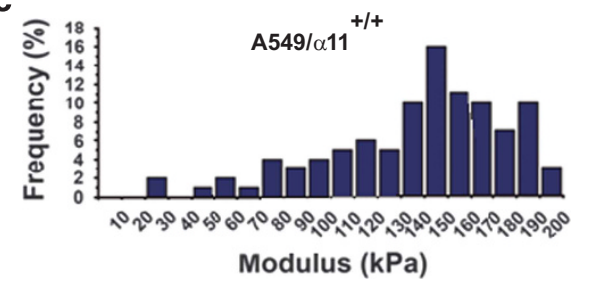

d

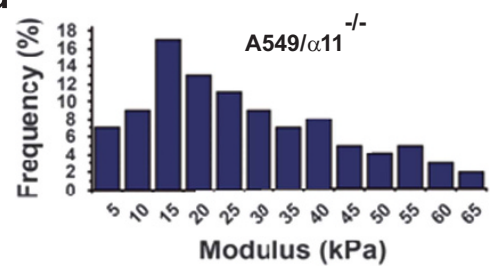

Figure 5. Collagen cross-linking accompanies lung cancer tumorigenesis. (a) Representatives are photomicrographs of A549 tumor xenograft sections. Photomicrographs of collagen fibers from tumor xenograft sections stained with PicroSirius red and viewed under parallel (top panel) and polarized light (middle panel) on widefield microscope (BX51, Olympus); scale bar, $25 \mu \mathrm{m}$. The bottom panel shows twophoton confocal SHG images of the tumor xenograft sections; scale bar, $100 \mu \mathrm{m}$. (b-d) Representative images of tissue samples and quantification of their stiffness distribution by AFM indicating the absence of $\alpha 11$ alters extracellular matrix organization in lung cancer xenograft model. (b) Height and deflection images collected from Digital Instrument Dimension 5000 AFM in contact mode; scale bar 1 um.

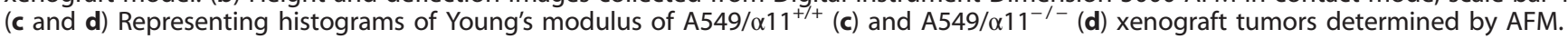

loss of tumor stromal a11 expression was correlated with decreased collagen stiffness. These results suggest a role for a11 in promoting NSCLC tumor progression by affecting the collagen stiffness of the tumor stroma.

Fibroblasts express the $\alpha 1 \beta 1, \alpha 2 \beta 1$ and $\alpha 11 \beta 1$ collagen-binding integrins. ${ }^{26}$ Of these, only $\alpha 2 \beta 1$ and $\alpha 11 \beta 1$ bind to and remodel the fibrillar form of collagen I present in collagen gels. Experimental data also suggest that collagen-binding ECM molecules, named COLINBRIS, with time are deposited in the collagen lattices, and binding of other integrins like av $\beta 3$ integrins to these bridging molecules also can mediate contraction of the collagen lattices. ${ }^{27}$

The integrin a11 chain in vivo displays a remarkable restricted expression in the human and mouse embryos, being restricted to subsets of fibroblasts. ${ }^{28,29}$ In the developing dermis, a11 expression is restricted to fibroblasts and no expression has been detected in other stromal cell types, such as vascular cells, immune cells or hematopoietic cell types. Furthermore, the fibroblast-restricted expression has been confirmed in transgenic reporter mice where $3 \mathrm{~kb}$ of the human ITGA11 promoter was able to drive a fibroblast-restricted expression. ${ }^{30}$ The dermal fibroblast-restricted expression of 011 in adult dermis has been confirmed in two independent studies. ${ }^{31,32}$ The tumor stroma formed in a11-deficient mice showed decreased Acta2 (which encodes for
a-SMA) expression. Data from other systems suggest that $\alpha 11 \beta 1$ is involved in myofibroblast differentiation. ${ }^{33,34}$ Because stiffness is a driving factor for myofibroblast differentiation, it is possible that reduced a11-dependent collagen organization and collagen cross-linking are contributing factors to lower SMA levels. Recently, it was shown that less granualtion tissue and less a-SMA-positive myofibroblasts formed in wounds from $\mathrm{a} 11^{-1-}$ mice. ${ }^{35}$ Our data suggest that a11 may regulate the differentiation and expression of a-SMA also in CAFs.

Our previous co-implantation studies using NSCLC cells and SV40-immortalized MEFs showed that a11 expression in MEFs significantly promotes tumorigenicity (exogenous stromal model). ${ }^{21}$ However, the result was tempered by the SV40immortalized MEF themselves being weakly tumorigenic. To directly confirm the tumor-promoting effect of stromal integrin a11, we have evaluated the growth of tumor cells in $a 11^{-1-}$ compared with their syngeneic wild-type $a 11^{+/+}$SCID mice (endogenous stromal model). We observed significantly reduced tumor growth of NSCLC cell lines in $\mathrm{a}_{111^{-/-}}$as compared with $\mathrm{a} 11^{+/+}$mice, thus strengthening the evidence for a11 being an important stromal factor in tumorigenicity of NSCLC cells.

The mouse downregulated genes were annotated to the Biocarta integrin-mediated signaling pathway. To validate this pathway, western blot analysis showed reduced levels of activated 
Table 1. Effect of Integrin $\alpha 11$ on tumor growth and metastasis of H460SM in mice

\begin{tabular}{|c|c|c|c|c|c|c|c|c|}
\hline \multirow[t]{2}{*}{ Experimental arms } & \multirow[t]{2}{*}{ Tumor take } & \multicolumn{2}{|c|}{ Regional mets (No. of animals) } & \multicolumn{3}{|c|}{ Systemic mets (No. of animals) } & \multicolumn{2}{|c|}{ No. of animals with systemic mets } \\
\hline & & $L N$ & L. lung & Bone & Kidney & Brain & Yes & No \\
\hline$\alpha 11^{+/-}(n=9)$ & 9 & 7 & 4 & 0 & 1 & 0 & 1 & 8 \\
\hline$\alpha 11^{-/-}(n=14)$ & 13 & 4 & 5 & 2 & 1 & 0 & 3 & 11 \\
\hline \multicolumn{9}{|c|}{$\begin{array}{l}\text { Abbreviations: L. lung, left lung; LN, lymph node; mets, metastasis. Incidence of systemic metastasis in orthotopic model using } \alpha 11 \text { SCID mice. The metastatic } \\
\text { potential of H460SM cells was demonstrated by endobronchially implanting } 1.0 \times 10^{6} \text { cells into the right caudal lobe of } \alpha 11^{-/-}, \alpha 11^{+/-} \text {and } \alpha 11^{+/+} \mathrm{SCID} \text { mice } \\
\text { Metastatic occurrences were assessed macroscopically and microscopically. Any visible tumor deposit other than the primary tumor was considered as } \\
\text { metastasis. Primary tumor weight and the weight of the mediastinal lymph node were measured to evaluate tumor burden. The H460SM cells produced } \\
\text { statistically significant systemic metastases }(12 / 16) \text { to brain, kidney, L. lung or bone in the } \alpha 11^{+/+} \text {animals when compared with } \alpha 11^{+/-} \text {or } \alpha 11^{-/-} \mathrm{SCID} \text { mice } \\
(P<0.0152) \text {. Fisher's exact test was used for comparison of the incidence of metastasis. }\end{array}$} \\
\hline
\end{tabular}

FAK and ERK $1 / 2$ in A549 tumor cell lysates from a $11^{-1-}$ compared with $a 11^{+/+}$mice. A role of FAK in macrophage and fibroblast migration is well established. ${ }^{36-38}$ Therefore, it is possible that the endogenous stromal model proceeds in a step-wise manner where the fibroblasts first proliferate, migrate, and then make contact with tumor cells. The tumor cells then respond to this contact by secreting growth factors such as transforming growth factor beta (TGF- $\beta$ ) that activate stromal fibroblasts to CAF. ${ }^{7}$ It has been shown that human mammary fibroblasts are converted into CAFs during the course of tumor progression in a breast tumor xenograft model. ${ }^{39}$ This effect occurs because of autocrine activating signaling loops, mediated by TGF- $\beta$ and stromal cell-derived factor-1 (SDF-1) cytokines. ${ }^{39}$ Consistent with this, ITGA11 promoter analysis has identified functional Smad-binding elements in the promoter. ${ }^{30}$ Furthermore, we previously reported that ITGA11 together with six other CAFs/tumor stroma genes act as transcriptional targets of the TGF- $\beta$ signaling pathway. ${ }^{22}$

As the tumorigenic role of a11 appears specific among the interstitial collagen-binding integrins, it is important to identify genes, especially ones encoding for other extracellular or secreted proteins that could be specifically regulated by integrin $a 11 \beta 1$. Among potential a11-regulated mouse genes, we demonstrated that the expression of Loxl1, was downregulated in xenograft tumors formed in $\mathrm{a}_{1} 1^{-/-}$as compared with $\mathrm{a} 11^{+/+}$mice. LOX family oxidases (LOX and LOXL 1-4) are collagen cross-linking enzymes $^{40}$ that influence tumor progression ${ }^{41}$ and metastasis. ${ }^{42}$ However, the role of LOXL1 in lung adenocarcinoma is not known. A recent study suggested that LOX in fibrotic lungs regulate myofibrobalst differentiation at the inflammatory phase. ${ }^{43}$ In our human microarray data, we observed that the expression of TGF $\beta R I$ is upregulated in A549 xenograft tumors in integrin $\mathrm{a} 11^{-/-}$as compared with $\mathrm{a} 11^{+/+}$mice, while in our mouse microarray data, the expression of Loxl1 is downregulated in A549 xenograft tumors in integrin $a 11^{-/-}$as compared with $a 11^{+/+}$ mice. Intriguingly, downregulation of TGF $\beta$ RII expression in conjunction with upregulation of lysyl oxidase (LOX), a gene homologous to LOXL1, has been associated with poorer patient prognosis in lung adenocarcinoma. ${ }^{41}$ The reduced TGFBRII expression in NSCLC has been associated with a more aggressive tumor behavior characterized by increased cell migration and increased TGF- $\beta 1$ synthesis, the latter suggested to attract immune cells. ${ }^{44}$

To evaluate possible interactions between the gene products in human tumor and mouse stromal cells, we applied human and mouse downregulated matrisomal genes in PPI networks. Our analysis suggest a link between extracellular (fibrillar collagens) and secreted (growth factors) proteins in tumor-stroma interactions. Collectively, the potential functional association of matrisomal deregulated genes in key pathways provides additional insight into how integrin a11 may affect CAF differentiation and tumorigenesis.

Reduced tumorigenicity in $\mathrm{a} 11^{-/-}$as compared with $\mathrm{a} 11^{+/+}$ mice was accompanied by disorganized collagen at the tumor cell/stroma interface. In tumor xenografts propagated in $a 11^{-/-}$ mice, total fibrillar collagen decreased as compared with $a 11^{+/+}$ mice. In addition, SHG imaging of tumor xenografts revealed the lack of reorganization of the fibrillar collagen adjacent to the developing epithelial lesions in $\mathrm{a}_{11} 1^{-/-}$as compared with $\mathrm{a} 11^{+/+}$ mice. Previous studies have suggested that reduced collagen cross-linking leads to repressed tumor progression. ${ }^{2}$ Moreover, collagen cross-linking in lung ECM promotes breast tumor metastasis, ${ }^{45}$ demonstrating that ECM organization and stiffness is a key regulator of tumor progression. In the current study, the strong association of a11 with collagen stiffness supports an interesting link between cancer cell and the induction of a supportive stroma, which favors cancer cell invasion and migration. CAFs appear to exert a direct physical impact on tumor tissues, ${ }^{46}$ resulting in increased ECM stiffness around tumor cells and consequently mechanical stress. Here, we have also demonstrated that integrin a11 has a pivotal role in the metastatic potential of NSCLC cells. The incidence of systemic metastasis to bone, brain, kidneys, lymph nodes and left lung was significantly lower in $a 11^{+/-}$and $a 11^{-/-}$compared with a $11^{+/+}(12 / 16)$ mice.

In summary, we have shown that stromal a11 expressed by CAFs has a significant effect on tumor growth and metastasis of NSCLC cells, and this appears to be associated with changes in the expression of genes involved in collagen cross-linking and collagen stiffness. Targeting a11 represents a potentially novel approach to treat NSCLC, especially in an adjuvant setting.

\section{MATERIALS AND METHODS}

Methods for PPI of mouse differentially expressed genes and networks are provided in detail in Supplementary Information.

\section{Animals and cell lines}

SCID mice were bred on-site and obtained from the Princess Margaret Cancer Centre (Toronto, ON, Canada) Animal Resource Center. All manipulations were done under sterile conditions in a laminar flow hood in accordance with protocols approved by the Institutional Animal Care Committee at the University Health Network (UHN). The general health of the animals was assessed daily. For more information on development of a11-deficient and immune-deficient mice, please refer to Supplementary Experimental Procedures.

$\mathrm{NCl}-\mathrm{H} 460 \mathrm{SM}, \mathrm{A} 549$ and primary human lung cancer cells (PHLC 178 and PHLC 655) were cultured at $37^{\circ} \mathrm{C}$ in RPMI 1640 media containing $10 \%$ fetal bovine serum. To culture primary human lung cancer cells, fragments of human lung tumors grown in SCID mice were processed into a single cell suspension to establish PHLC 178 and PHLC 655 cell lines. ${ }^{47}$ Tumor fragments were minced and then digested with collagenase at $37^{\circ} \mathrm{C}$ for $1 \mathrm{~h}$. 
Next, cells were treated with DNase at $37^{\circ} \mathrm{C}$ for $10 \mathrm{~min}$ and re-suspended in RPMI 1640 media with $10 \%$ fetal bovine serum to end the dissociation. Magnetic columns (MACS Technology, Santa Barbara, CA, USA) coated with $\mathrm{H} 2 \mathrm{~Kb} / \mathrm{H} 2 \mathrm{Dd}$ anti-mouse antibodies were used to isolate human cells from mouse fibroblast cells in the cell population.

\section{Subcutaneous tumorigenicity assay}

a11 SCID mice were bred on-site at the Ontario Cancer Institute animal facility. All manipulations were done under sterile conditions in a laminar flow hood, in accordance with protocols approved by the UHN Animal Care Committee. Tumor cells $\left(2 \times 10^{6}\right)$ were implanted subcutaneously into the abdominal flank of 6 -week-old male $a 11^{+/+}$and $a 11^{-1-}$ SCID mice. Tumor growth was assessed as previously described. ${ }^{48}$

Orthotopic model to evaluate metastatic potential of a11

Three groups of SCID mice, $\mathrm{a} 11^{+/+}(n=16), \mathrm{a} 11^{+/-}(n=10)$ and $\mathrm{a} 11^{-/-}$ $(n=15)$ were assigned for orthotopic implantation of H460SM cells. Animal deaths occurring less than 21 days post implantation were considered to be due to surgical-related complications and were excluded from the final comparative analysis. When any animal from any group succumbed to the disease or demonstrated terminal sign and symptoms, a single animal from each of the other groups was killed. This allows a direct comparison of all groups at the same time point for tumor metastatic potential. Survival was not an end point of the study.

The procedure for endobronchial tumor cell implantation in rodent was previously reported in detail. ${ }^{25}$ Mice were anesthetized by intraperitoneal injection of Ketamine $(80 \mathrm{mg} / \mathrm{kg})$ and Xylazine $(10 \mathrm{mg} / \mathrm{kg})$. Cultured cells were harvested by trypsinization and adjusted to a final concentration of $1 \times 10^{6}$ cells $/ 20 \mu \mathrm{l}$ for endobronchial implantation using a 24-gauge, 0.75 -inch-long Teflon catheter. The catheter was passed into the distal bronchus of right caudal lobe through a small tracheotomy incision. The cell suspension was injected. After withdrawal of the catheter, the tracheotomy was repaired with a 6-0 Proline suture (Ethicon, Inc, Sommerville, NJ, USA), and the incision was closed with sterile wound clips. The mice were returned to their cages on sterile rolled drapes to maintain their semi-upright position. The animals were given antibiotics Baytril (Bayer, Mississauga, ON, Canada) in water for 1 week postoperatively. The assessment of metastatic potential is described in Supplementary Materials and Methods.

\section{Reverse transcriptase-quantitative polymerase chain reaction} (RT-qPCR) assay

Total RNA was extracted from CAF, NSCLC tumor cell lines and two pooled samples of xenograft tumors arisen in $\mathrm{a}_{1} 1^{-1-}$ and $\mathrm{a} 11^{+++}$SCID mice. Each pool consisted of four tumors. Following this, total RNA $(2 \mu \mathrm{g})$ was reverse-transcribed using Superscript II reverse transcriptase (Invitrogen, Burlington, ON, Canada). A 10 ng equivalent of complementary DNA was used for each quantitative PCR assay performed with the Stratagene Mx3000p Sequence detection System using SYBR green $2 x$ master mix (Stratagene, La Jolla, CA, USA). To verify the lack of a 11 mRNA in $a 11^{-1-}$ SCID mice, RT-qPCR was carried out using RNA from the tail tissue and primers corresponding to the exon 2 and 3 of mouse Itga11 sequence:

Forward $5^{\prime}$-tcacggacaccttcaatatggatac- $3^{\prime}$ and Reverse $5^{\prime}$-gaa tctgaagt tggagttgacccgt-3'. Human- and mouse-specific primers were used to detect the gene expression of ITGA11 and LOXL1: human ITGA11 (forward $5^{\prime}$ - gatgggctcatcgacctg-3' and reverse $5^{\prime}$-acagaatcacagcgttgcc- $\left.3^{\prime}\right)$. Human LOXL1 (forward 5'-gtcgctacgtttctgcaaca-3' and reverse 5'- gctttggaag gggagagatt- $3^{\prime}$ ) and mouse Lox/1 (forward $5^{\prime}$ - ggcctcagggagtgaacat $-3^{\prime}$ and reverse $5^{\prime}$ - caatcttgctgtgtgggatg $-3^{\prime}$ ).

To validate the microarray studies, 11 up- and downregulated human genes and 8 downregulated mouse genes in A549 xenograft tumors in a $11^{-1-}$ versus $a 11^{+/+}$SCID mice were selected in the correlation analysis. Genes that had higher fold change were selected: human genes (up: HNRNPK, TXNRPD1, CNBP, SPP1, RNASE4, EEF1A1. down: EHD2, CRYAB, HSPA1B, TMEM132A, HSPA1A) (for primers list, please refer to Supplementary Table S1a) and mouse genes (down: Wisp2, Loxl1, Gpc1, Igfbp4, Bgn, Ltbp3, Grn, Plod3) (for primers list, please refer to Supplementary Table S1b) were tested in the correlation analysis. Predicted PCR product sequences were verified using BLAST for recognition of target and non-target sequences. Dissociation curves were performed as routine verification to check the primers for amplification of a single band, and template dilution standard curves ( 5 log range) were conducted with each primer set to verify a linear relationship between template concentration and $\mathrm{Ct}$ values $\left(\mathrm{R}^{2}>0.9\right)$.

\section{Western blot analysis}

To extract total protein, two pooled samples of eight xenograft tumors in $\mathrm{a} 11^{+/+}$and $\mathrm{a} 11^{-/-}$mice were homogenized in lysis buffer (1\% Triton X-100, $10 \%$ glycerol, $50 \mathrm{~mm}$ Hepes, $150 \mathrm{~mm} \mathrm{NaCl}, 1.5 \mathrm{~mm} \mathrm{MgCl} 2,10 \mathrm{~mm}$ sodium pyrophosphate, $100 \mathrm{~mm} \mathrm{NaF}, 10 \mathrm{~mm}$ Na4P2O4, $1 \mathrm{~mm}$ EDTA, $10 \mathrm{mg} /$ $\mathrm{ml}$ aprotinin, $10 \mathrm{mg} / \mathrm{ml}$ leupeptin, $100 \mathrm{mg} / \mathrm{ml}$ PMSF and $1 \mathrm{~mm}$ sodium orthovanadate), and the lysates were cleared by centrifugation. Protein samples were fractionated on sodium dodecyl sulfate/polyacrylamide gels and transferred to polyvinylidenefluoride membranes. The membranes were blocked with 5\% non-fat dry milk and incubated with primary antibodies to human $\mathrm{a} 11{ }^{49} \mathrm{FAK}^{\mathrm{PY} 397}, \mathrm{FAK}^{\mathrm{pY} 925}$, total FAK, MAPK ${ }^{\mathrm{PY} 44 / 42}$, total MAPK, Src ${ }^{\text {pY416, }}$, total Src, Akt ${ }^{5473}$, total Akt (Cell Signaling, Danvers, MA, USA) and LOXL1 (Santa Cruz, Dallas, TX, USA) at 1:1000 dilution. Visualization used horseradish peroxidase-linked anti-rabbit and antimouse secondary antibodies (Cell Signaling) and ECL-Plus blotting substrate detection kit (GE Healthcare Life Sciences, Mississauga, ON, Canada).

\section{Immunostaining and imaging}

Cryosections ( 5 microns thick) of xenograft tumors were fixed in cold acetone for $5 \mathrm{~min}$, rehydrated in phosphate-buffered saline and blocked using $10 \%$ bovine serum albumin. Following phosphate-buffered saline rinses, the slides were incubated with a primary antibody, rabbit polyclonal-anti integrin a11 affinity-purified antibody at the dilution of 1:500 and a mixture of mouse monoclonal cytokeratin antibodies (AE1/AE3, Dako, Burlington, ON, Canada) composed of an equal mixture of AE1/AE3 at the dilution of 1:200 for $1 \mathrm{~h}$ at $37^{\circ} \mathrm{C}$. Following phosphatebuffered saline/Tween $0.05 \%$ washes, the cryosections were incubated for $1 \mathrm{~h}$ at room temperature with Cy5-conjugated goat anti-rabbit Ig G (1:100 dilution; Jackson Immunology Laboratory, Bar Harbor, MA, USA) and Cy3-conjugated goat anti-mouse IgG (1:800 dilution; Jackson Laboratory) secondary antibodies. The slides were mounted in Vectashield mounting medium (Vector Laboratories, Burlingame, CA, USA) for fluorescence microscopy.

Fibrillar collagen was visualized in 5 - $\mu$ m-thick paraffin sections of xenograft tumors using $0.1 \%$ PicroSirius Red staining. Sections were imaged with polarized-light microscopy using parallel and perpendicular polarizer orientations on an Olympus (Richmond Hill, ON, Canada) BX51 microscope.

Serial sections $(5 \mu \mathrm{m}$ thick) from formalin-fixed paraffin-embedded blocks of xenograft tumors were stained for hematoxylin and eosin and PicroSirius red staining using PicroSirius red stain kit (Polysciences, Warrington, PA, USA). These histological sections were also immunostained for rabbit polyclonal anti-cytokeratin (PanCK, 1:3000, Dako) and mouse monoclonal anti-a-SMA (1:400, Dako).

\section{SHG imaging and quantitation of collagen organization}

SHG imaging is a powerful method of illuminating collagen fibrils in tissue irrespective of their orientation. ${ }^{50-52}$ Unstained fixed and deparaffinized tissue sections were mounted and visualised under a Zeiss (Toronto, ON, Canada) LSM510 NLO multi-photon microscope, equipped with a femtosecond laser (Coherent Chameleon) tuned to $840 \mathrm{~nm}$. The SHG signal is collected at exactly one-half of the illumination wavelength (that is, $420 \mathrm{~nm}$ ) using a narrow bandpass filter. Confocal detection is not required owing to the two-photon illumination, so the detector pinhole was opened wide to collect the most signal. Autofluorescence is generated in the tissue at the same time, so this was collected in a separate detection channel using a $450-600 \mathrm{~nm}$ bandpass filter. The percentage of the autofluorescence image (typically about $20 \%$ ) was subtracted from the SHG image to obtain a pure SHG image, representing only fibrillar collagen.

The background-corrected SHG images were analyzed using a novel relative linearity index that we have developed based on established texture analysis ${ }^{53}$ available as a plugin for the freeware Image $\mathrm{J}$ analysis software (http://imagej.nih.gov/ij/index.html). The grey-level co-occurrence matrix Texture Analysis plugin in Image $J$ was used to evaluate the correlation of pixels in a given direction, which is a measure of linearity in that direction. Rotating the SHG images in 15 degree increments through 180 degrees gives the linearity as a function of direction. The difference between the maximum and minimum linearity values through the rotation gives a robust measure of whether collagen fibrils are organized randomly 
or whether they have a preferred direction: a relatively high number indicates more linear structures in the image and a relatively low number indicates random orientation of the collagen fibrils.

\section{Atomic force microscopy}

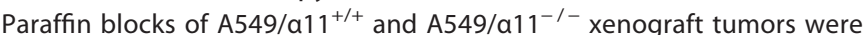
cut into $10-\mu \mathrm{m}$-thick sections. Prior to the AFM measurement, each section was immunostained with hematoxylin and eosin to define the stroma-rich regions. The samples were maintained in phosphatebuffered saline during the AFM session. Three xenograft tumor sections

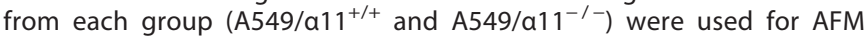
quantification of Young's elastic modulus of the cancer-associated stroma. AFM indentations were performed using an MFP-3D AFM (Asylum Research, Santa Barbara, CA, USA). Silicon nitride cantilevers (Bruker, Goleta, CA, USA) with a nominal spring constant of $0.06 \mathrm{~N} / \mathrm{m}$ were used. Accurate spring constant was determined using thermal noise method before each measurement. ${ }^{54}$ Samples were indented at a $1 \mu \mathrm{m} / \mathrm{s}$ loading rate, ramp size of $5 \mu \mathrm{m}$ and with a maximum force of $500 \mathrm{pN}$. The Young's modulus was determined by considering loadindentation dependence for a paraboloidal tip shape. The determination of the elastic modulus of the tissue (E1) from force-distance curves was performed using the Hertz model (Equation 1)..$^{55,56}$

$$
F=\frac{4 \sqrt{R}}{3\left(1-v^{2}\right)} E \delta^{3 / 2}
$$

Where $F$ is the loading force $(\mathrm{N}), \mathrm{E}$ is the Young's modulus $(\mathrm{Pa}), v$ is the Poisson ratio, $R$ is the radius of curvature of the tip $(\mathrm{m})$ and $\delta$ is the indentation depth $(\mathrm{m})$. Tissue samples were assumed to be incompressible and a Poisson's ratio of 0.5 was used in the calculation of the Young's elastic modulus.

\section{Statistical analysis}

Differences in tumor growth rates of xenografts were tested using mixed effect model estimation. ${ }^{57}$ Chi-Square and Fisher exact test were used for metastatic experiments and $t$ test for qRT-PCR assays.

\section{CONFLICT OF INTEREST}

The authors declare no conflict of interest.

\section{ACKNOWLEDGEMENTS}

This work was supported by grants from the Canadian Cancer Society (\# 019293 and \# 020527), Canadian Institutes of Health Research grant MOP-115174, Terry Fox Foundation STIHR, CIHR grant TGT-53912 (BB), Norwegian Centre of Excellence grant, The Research Council of Norway grants 223250 (DG) and the Ontario Ministry of Health and Long Term Care. Dr Tsao is the M. Qasim Choksi chair in Lung Cancer Translational research. Dr Jurisica is the Canada Research Chair in Integrative Computational Biology. The data reported in this paper have been deposited into the Gene Expression Omnibus (GEO) database, http://ncbi.nlm.nih.gov/geo/ (accession no. GSE51722).

\section{AUTHOR CONTRIBUTIONS}

$R N, E P, K K, J H, J L, J J, M B, B B, Y W, K V, E l, N A P, C N, N R$ and AL performed the experiments. RN, DS, CT, CJP, JJ, MB, BB, El, CQZ, MP, DW and IJ analyzed the data. MST and RN designed the experiments. MST, RN, DS, CT, EP, KK, JH, JJ, MB, $\mathrm{El}, \mathrm{IJ}, \mathrm{DG}$ and GW wrote the manuscript.

\section{REFERENCES}

1 Egeblad M, Ewald AJ, Askautrud HA, Truitt ML, Welm BE, Bainbridge E et al. Visualizing stromal cell dynamics in different tumor microenvironments by spinning disk confocal microscopy. Dis Model Mech 2008; 1: 155-167; discussion 165 .

2 Levental KR, Yu H, Kass L, Lakins JN, Egeblad M, Erler JT et al. Matrix crosslinking forces tumor progression by enhancing integrin signaling. Cell 2009; 139: 891-906.

3 Lin EY, Li JF, Gnatovskiy L, Deng Y, Zhu L, Grzesik DA et al. Macrophages regulate the angiogenic switch in a mouse model of breast cancer. Cancer Res 2006; 66: 11238-11246
4 Provenzano PP, Eliceiri KW, Campbell JM, Inman DR, White JG, Keely PJ. Collagen reorganization at the tumor-stromal interface facilitates local invasion. BMC Med 2006; 4: 38.

5 Ostman A, Augsten M. Cancer-associated fibroblasts and tumor growth--bystanders turning into key players. Curr Opin Genet Dev 2009; 19: 67-73.

6 Gaggioli C, Hooper S, Hidalgo-Carcedo C, Grosse R, Marshall JF, Harrington K et al. Fibroblast-led collective invasion of carcinoma cells with differing roles for RhoGTPases in leading and following cells. Nat Cell Biol 2007; 9: 1392-1400.

7 Kalluri R, Zeisberg M. Fibroblasts in cancer. Nat Rev Cancer 2006; 6: 392-401.

8 Provenzano PP, Cuevas C, Chang AE, Goel VK, Von Hoff DD, Hingorani SR. Enzymatic targeting of the stroma ablates physical barriers to treatment of pancreatic ductal adenocarcinoma. Cancer Cell 2012; 21: 418-429.

9 Nakasone ES, Askautrud HA, Kees T, Park JH, Plaks V, Ewald AJ et al. Imaging tumor-stroma interactions during chemotherapy reveals contributions of the microenvironment to resistance. Cancer Cell 2012; 21: 488-503.

10 Barczyk M, Carracedo S, Gullberg D. Integrins. Cell Tissue Res 2010; 339: 269-280.

11 Desgrosellier JS, Cheresh DA. Integrins in cancer: biological implications and therapeutic opportunities. Nat Rev Cancer 2010; 10: 9-22.

12 Gullberg DE, Lundgren-Akerlund E. Collagen-binding I domain integrins--what do they do? Prog Histochem Cytochem 2002; 37: 3-54.

13 Popova SN, Lundgren-Akerlund E, Wiig H, Gullberg D. Physiology and pathology of collagen receptors. Acta Physiol (Oxf) 2007; 190: 179-187.

14 Knight CG, Morton LF, Onley DJ, Peachey AR, Messent AJ, Smethurst PA et al. Identification in collagen type I of an integrin alpha2 beta1-binding site containing an essential GER sequence. J Biol Chem 1998; 273: 33287-33294.

15 Knight CG, Morton LF, Peachey AR, Tuckwell DS, Farndale RW, Barnes MJ. The collagen-binding A-domains of integrins alpha(1)beta(1) and alpha(2)beta(1) recognize the same specific amino acid sequence, GFOGER, in native (triplehelical) collagens. J Biol Chem 2000; 275: 35-40.

16 Zhang WM, Kapyla J, Puranen JS, Knight CG, Tiger CF, Pentikainen OT et al. alpha 11 beta 1 integrin recognizes the GFOGER sequence in interstitial collagens. J Biol Chem 2003; 278: 7270-7277.

17 Jokinen J, Dadu E, Nykvist P, Kapyla J, White DJ, Ivaska J et al. Integrin-mediated cell adhesion to type I collagen fibrils. J Biol Chem 2004; 279: 31956-31963.

18 Popova SN, Barczyk M, Tiger CF, Beertsen W, Zigrino P, Aszodi A et al. Alpha11 beta1 integrin-dependent regulation of periodontal ligament function in the erupting mouse incisor. Mol Cell Biol 2007; 27: 4306-4316.

19 Barczyk MM, Olsen LH, da Franca P, Loos BG, Mustafa K, Gullberg D et al. A role for alpha11beta1 integrin in the human periodontal ligament. J Dent Res 2009; 88: 621-626.

20 Wang KK, Liu N, Radulovich N, Wigle DA, Johnston MR, Shepherd FA et al. Novel candidate tumor marker genes for lung adenocarcinoma. Oncogene 2002; 21: 7598-7604.

21 Zhu CQ, Popova SN, Brown ER, Barsyte-Lovejoy D, Navab R, Shih W et al. Integrin alpha 11 regulates IGF2 expression in fibroblasts to enhance tumorigenicity of human non-small-cell lung cancer cells. Proc Natl Acad Sci USA 2007; 104: 11754-11759.

22 Navab R, Strumpf D, Bandarchi B, Zhu CQ, Pintilie M, Ramnarine VR et al. Prognostic gene-expression signature of carcinoma-associated fibroblasts in nonsmall cell lung cancer. Proc Natl Acad Sci USA 2011; 108: 7160-7165.

23 Pietras K, Ostman A. Hallmarks of cancer: interactions with the tumor stroma. Exp Cell Res 2010; 316: 1324-1331.

24 Blumbach K, Niehoff A, Belgardt BF, Ehlen HW, Schmitz M, Hallinger R et al. Dwarfism in mice lacking collagen-binding integrins alpha2beta1 and alpha11beta1 is caused by severely diminished IGF-1 levels. J Biol Chem 2012; 287: 6431-6440.

25 Liu J, Blackhall F, Seiden-Long I, Jurisica I, Navab R, Liu N et al. Modeling of lung cancer by an orthotopically growing H460SM variant cell line reveals novel candidate genes for systemic metastasis. Oncogene 2004; 23: 6316-6324.

26 Zeltz C, Lu N, Gullberg D. Integrin alpha11beta1: a major collagen receptor on fibroblastic cells. Adv Exp Med Biol 2014; 819: 73-83.

27 Zeltz C, Orgel J, Gullberg D. Molecular composition and function of integrin-based collagen glues-Introducing COLINBRIs. Biochim Biophys Acta 2014; 1840: 2533-2548.

28 Tiger CF, Fougerousse F, Grundstrom G, Velling T, Gullberg D. alpha11beta1 integrin is a receptor for interstitial collagens involved in cell migration and collagen reorganization on mesenchymal nonmuscle cells. Dev Biol 2001; 237: 116-129.

29 Popova SN, Rodriguez-Sanchez B, Liden A, Betsholtz C, Van Den Bos T, Gullberg D. The mesenchymal alpha11beta1 integrin attenuates PDGF-BBstimulated chemotaxis of embryonic fibroblasts on collagens. Dev Biol 2004; 270: 427-442.

30 Lu N, Carracedo S, Ranta J, Heuchel R, Soininen R, Gullberg D. The human alpha11 integrin promoter drives fibroblast-restricted expression in vivo and is regulated 
by TGF-beta1 in a Smad- and Sp1-dependent manner. Matrix Biol 2010; 29: $166-176$

31 Svendsen OS, Barczyk MM, Popova SN, Liden A, Gullberg D, Wiig H. The alpha11beta1 integrin has a mechanistic role in control of interstitial fluid pressure and edema formation in inflammation. Arterioscler Thromb Vasc Biol 2009; 29: 1864-1870.

32 Zweers MC, Davidson JM, Pozzi A, Hallinger R, Janz K, Quondamatteo F et al. Integrin alpha2beta1 is required for regulation of murine wound angiogenesis but is dispensable for reepithelialization. J Invest Dermatol 2007; 127: 467-478.

33 Carracedo S, Lu N, Popova SN, Jonsson R, Eckes B, Gullberg D. The fibroblast integrin alpha11beta1 is induced in a mechanosensitive manner involving activin A and regulates myofibroblast differentiation. J Biol Chem 2010; 285: 10434-10445.

34 Talior-Volodarsky I, Connelly KA, Arora PD, Gullberg D, McCulloch CA. alpha11 integrin stimulates myofibroblast differentiation in diabetic cardiomyopathy. Cardiovasc Res 2012; 96: 265-275.

35 Schulz JN, Zeltz C, Sorensen IW, Barczyk M, Carracedo S, Hallinger R et al. Reduced granulation tissue and wound strength in the absence of alpha11beta1 integrin. J Invest Dermatol 2015; 135: 1435-1444.

36 Owen KA, Pixley FJ, Thomas KS, Vicente-Manzanares M, Ray BJ, Horwitz AF et al. Regulation of lamellipodial persistence, adhesion turnover, and motility in macrophages by focal adhesion kinase. J Cell Biol 2007; 179: 1275-1287.

37 Tilghman RW, Slack-Davis JK, Sergina N, Martin KH, Iwanicki M, Hershey ED et al. Focal adhesion kinase is required for the spatial organization of the leading edge in migrating cells. J Cell Sci 2005; 118: 2613-2623.

38 Mitra SK, Hanson DA, Schlaepfer DD. Focal adhesion kinase: in command and control of cell motility. Nat Rev Mol Cell Biol 2005; 6: 56-68.

39 Kojima Y, Acar A, Eaton EN, Mellody KT, Scheel C, Ben-Porath I et al. Autocrine TGF-beta and stromal cell-derived factor-1 (SDF-1) signaling drives the evolution of tumor-promoting mammary stromal myofibroblasts. Proc Natl Acad Sci USA 2010; 107: 20009-20014.

40 Yamauchi M, Shiiba M. Lysine hydroxylation and cross-linking of collagen. Methods Mol Biol 2008; 446: 95-108.

41 Wilgus ML, Borczuk AC, Stoopler M, Ginsburg M, Gorenstein L, Sonett JR et al. Lysyl oxidase: a lung adenocarcinoma biomarker of invasion and survival. Cancer 2011; 117: 2186-2191.

42 Xiao Q, Ge G. Lysyl oxidase, extracellular matrix remodeling and cancer metastasis. Cancer Microenviron 2012; 5: 261-273.

43 Cheng T, Liu Q, Zhang R, Zhang Y, Chen J, Yu R et al. Lysyl oxidase promotes bleomycin-induced lung fibrosis through modulating inflammation. J Mol Cell Biol 2014; 6: 506-515.

44 Malkoski SP, Haeger SM, Cleaver TG, Rodriguez KJ, Li H, Lu SL et al. Loss of transforming growth factor beta type II receptor increases aggressive tumor behavior and reduces survival in lung adenocarcinoma and squamous cell carcinoma. Clin Cancer Res 2012; 18: 2173-2183.
45 Erler JT, Bennewith KL, Cox TR, Lang G, Bird D, Koong A et al. Hypoxia-induced lysyl oxidase is a critical mediator of bone marrow cell recruitment to form the premetastatic niche. Cancer Cell 2009; 15: 35-44.

46 Xing F, Saidou J, Watabe K. Cancer associated fibroblasts (CAFs) in tumor microenvironment. Front Biosci 2010; 15: 166-179.

47 John T, Kohler D, Pintilie M, Yanagawa N, Pham NA, Li M et al. The ability to form primary tumor xenografts is predictive of increased risk of disease recurrence in early-stage non-small cell lung cancer. Clin Cancer Res 2011; 17: 134-141.

48 Navab R, Liu J, Seiden-Long I, Shih W, Li M, Bandarchi B et al. Co-overexpression of Met and hepatocyte growth factor promotes systemic metastasis in $\mathrm{NCl}-\mathrm{H} 460$ non-small cell lung carcinoma cells. Neoplasia 2009; 11: 1292-1300.

49 Velling T, Kusche-Gullberg M, Sejersen T, Gullberg D. cDNA cloning and chromosomal localization of human alpha(11) integrin. A collagen-binding, I domain-containing, beta(1)-associated integrin alpha-chain present in muscle tissues. J Biol Chem 1999; 274: 25735-25742.

50 Williams RM, Zipfel WR, Webb WW. Interpreting second-harmonic generation images of collagen I fibrils. Biophys J 2005; 88: 1377-1386.

51 Brown E, McKee T, diTomaso E, Pluen A, Seed B, Boucher Y et al. Dynamic imaging of collagen and its modulation in tumors in vivo using second-harmonic generation. Nat Med 2003; 9: 796-800.

52 Campagnola PJ, Loew LM. Second-harmonic imaging microscopy for visualizing biomolecular arrays in cells, tissues and organisms. Nat Biotechnol 2003; 21: 1356-1360.

53 Haralick RM, Shanmugam K, Dinstein I. Textural features for image classification. IEEE Transactions on Systems, Man, and Cybernetics 1973; SMC-3: 610-621.

54 Hutter JL, Bechhoefer J. Calibration of atomic-force microscope tips. Rev Sci Instrum 1993; 64: 1868-1873.

55 Hertz H. Über die Berührung fester elastischer Körper. J Reine Angewandte Mathematik 1882; 92: 156-171.

56 Sneddon I. The relation between load and penetration in the axisymmetric boussinesq problem for a punch of arbitrary profile. Int J Eng Sci 1965; 3: 47-57.

57 Littell RC, Henry PR, Ammerman CB. Statistical analysis of repeated measures data using SAS procedures. J Anim Sci 1998; 76: 1216-1231.

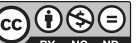

This work is licensed under a Creative Commons AttributionNonCommercial-NoDerivs 4.0 International License. The images or other third party material in this article are included in the article's Creative Commons license, unless indicated otherwise in the credit line; if the material is not included under the Creative Commons license, users will need to obtain permission from the license holder to reproduce the material. To view a copy of this license, visit http:// creativecommons.org/licenses/by-nc-nd/4.0/

Supplementary Information accompanies this paper on the Oncogene website (http://www.nature.com/onc) 